\title{
Scripts people live in the marketplace: an application of script analysis to Confessions of a Shopaholic
}

Article

Accepted Version

Molesworth, M. and Grigore, G. (2019) Scripts people live in the marketplace: an application of script analysis to Confessions of a Shopaholic. Marketing Theory, 19 (4). pp. 467-488. ISSN 1741-301X doi:

https://doi.org/10.1177/1470593118821725 Available at https://centaur.reading.ac.uk/79093/

It is advisable to refer to the publisher's version if you intend to cite from the work. See Guidance on citing.

To link to this article DOI: http://dx.doi.org/10.1177/1470593118821725

Publisher: Sage

All outputs in CentAUR are protected by Intellectual Property Rights law, including copyright law. Copyright and IPR is retained by the creators or other copyright holders. Terms and conditions for use of this material are defined in the End User Agreement.

www.reading.ac.uk/centaur 
Central Archive at the University of Reading

Reading's research outputs online 


\title{
Scripts people live in the marketplace: An application of Script Analysis to
}

\section{Confessions of a Shopaholic}

\begin{abstract}
This paper shows how Script Analysis can produce new marketing theory by applying it to contemporary shopping behaviour via British novelist Madeleine Wickham's novel, Confessions of a Shopaholic. We show how Becky Bloomwood, the central character, is a Scripted Shopaholic for whom shopping is the activity around which everything else in her live falls in and out of place. In presenting a Scripted Shopaholic Racket System, we theorise: how shopping is used to structure time and relationships with others; the role of injunctions and attributions and related discounting in fulfilling shopping scripts; and, the possibility of freedom from excessive shopping scripts. We therefore bring together psychoanalysis, literary texts, and shopping theories to generate new insights about why people shop (and often shop too much), and how such behaviours might be transformed.
\end{abstract}

Keywords: shopping, Script Analysis, Shopaholic, Racket System, popular fiction

\section{Introduction}

Despite enduring complaints that overconsumption is bad for society (Marcuse, 1964), psychological wellbeing (Fromm, 1976), and individual indebtedness (Black, 2007), shopping remains a prominent part of Western culture. Hence in British novelist Madeleine Wickham's bestselling Shopaholic books, shopping is not just a way to acquire goods and services, or even just a source of distracting pleasure, but the problematic, yet essential purpose of Becky Bloomwood's life, work, ambitions, and relationships that resonates with millions of readers. Consistent with the established use of fiction in marketing theory (Brown, 1995; Fitchett, 2002; Patterson and Brown, 2005; Patsiaouras et al., 2016), we use Confessions of a 
Shopaholic to argue that unlike oniomania, the rare but debilitating psychological condition of compulsive shopping, the Shopaholic Script Racket System is an important feature of contemporary consumer culture. Specifically, we explain: (1) how shopping is used to structure time and relationships with others; and, (2) the role of market and parental injunctions and attributions, and related discounting in consumer shopping scripts.

We contribute to marketing theory by deploying post-psychoanalytic Script Analysis to provide a reading of Becky Bloomwood. This provides insights into how shopping offers emotionally rich routines with predictably dramatic outcomes, as the basis for dealing with the world, achieving existential recognition, and ultimately fulfilling a life-script. In taking this approach, we respond to calls for a re-appreciation of psychoanalysis in management theory in general (Gabriel and Carr, 2002; Mindgley, 2006; Holmes, 2013), and marketing theory specifically (Fitchett, 2002; Chatzidakis, 2014; Cluley, 2015; Cluley and Desmond, 2015; Miles, 2015; Patsiaouras et al., 2016; Molesworth et al., 2017).

We first review theories of shopping, including how compulsive shopping is narrowly defined as a way to distance dysfunctional shopping from consumer culture, and which we must therefore distance our analysis from. We then explain Script Analysis as an analytic that sheds light on why people shop, and that connects individual scripts to fairy tales, including those in popular fiction. This allows us to theorise consumer scripting, based on a textual analysis of the central character in the Shopaholic book series. Finally, we discuss implications for marketing theory.

\section{Theories of shopping}

Shopping has long been recognised as significant in people's lives. As Falk and Campbell (1997:8) note, shopping represents 'a fundamental shift in the structuring principle of society from production to consumption'. And as Twitchell (1999) enthusiastically explains: 
'[shopping] has proven potent because human beings love things...we live for things...we live through things. We create ourselves through things'. As early as Walter Benjamin's exploration of the Paris arcades, shopping has been described as something more that the functional acquisition of goods, and as Miller (1997) notes, even Benjamin's critical approach may be repurposed to present shopping as something that 'matters'. Indeed, despite the dominance of buyer behaviour in the marketing literature, with its narrow focus on purchase decisions (Baumestein, 2007; Solomon, 2014), there persists an acknowledgement that shopping serves broader social functions (Tauber, 1972; Arnold and Reynolds, 2003; Miller, 1997, 1998, 2008, 2010).

Following early conceptualisations of shopping motives, research has become focused on utilitarian, hedonic, social, or critical discourses. Utilitarian approaches to buyer behaviour deal with shopping as a benign and incidental, if necessary, aspect of life that ignores the complex relational dynamics that we wish to deal with here. We therefore now review approaches that recognise shopping as pleasurable and social, or potentially damaging and dominating. Although such theoretical ambivalence is ongoing, throughout these discourses we note a broad acceptance of the importance of shopping to people. Yet fear of shopping too much has also resulted in a separation of dysfunctional shopping from its everyday forms. As we explore consumer scripting we will note a partial synthesis of such contradictory claims, i.e., that shopping may be social, pleasurable and central to life-scripts, even as those scripts may be problematic.

\section{The comforts of shopping}

Tauber's (1972) classic review of shopping remains an important starting point for understanding shopping as a social practice. Tauber (1972:48) states that a person shops when he/she 'needs attention, wants to be with peers, desires to meet people with similar interests, 
feels a need to exercise, or simply has leisure time', recognising the centrality of shopping in peoples' lives, as it provides role-playing activities, escapism, and the alleviation of depression. He further emphasised social motives such as communication with others, a desire for status (where shoppers receive attention from the store personnel), and the egocentred pleasure of negotiating. Yet, absent is an explanation of how shopping comes to be so important, or how these functions may form part of a biographical consumer script.

Thirty years later, Arnold and Reynolds (2003) developed a different shopping scale that also recognises shopping as a self-gratifying activity for getting one's mind off problems and boosting the ego, as well as the pleasures of value shopping for sales, and related enhanced self-esteem. The authors further highlight shopping for socialising and bonding with others, and the idea that shopping satisfies a need for structure, again suggesting that shopping may be a central practice in people's lives.

Within such discourses, however, there is a tendency to see shopping as a consciously chosen activity, where agentic individuals decide to shop for one reason or another. Methodologically and theoretically, scales or taxonomies are therefore deployed in ways that offer a snapshot of attitudes or behaviours at a certain point in time (also see Lunt, 1995). Similar to Giesler and Thompson's (2016) complaint about variance analysis, such discourse cannot theorise shopping as a biographical process that unfolds over time and throughout the life of an individual, ignoring psychological roots in favour of social functions.

Miller's ethnographic approach $(1997,1998,2008,2010)$ also argues that shopping represents social relations, especially love, care, and sacrifice, rather than merely utility, or the hedonic pleasures of materialism. This better captures a biographical trajectory. For example, saving, for Miller, recognises that the future is more important than the current satisfaction of desire; whilst spending enacts ideal relationships with others (1998), and may even act as a release of (sexual) tension (1997). Miller's Theory of Shopping (1998) is 
therefore biographical and social, albeit with an anthropological frame. His later work maintains that far from material things replacing human relationships, the stronger our relationships with objects, the stronger is our relationship with the people they represent to us (Miller, 2008). In The Comfort of Things, Miller (2008) notes a biographical basis of relations between people and objects - especially in the parental injunctions of loneliness in 'Empty', contrasted with the loving family bonds in 'Full', even though he does not explicitly theorise the apparent scripting he identifies in everyday material rituals.

Together these studies highlight positive (or at least meaningful) outcomes of shopping, downplaying potential negative consequences. Indeed, Miller $(1997,2008,2010)$ is especially unenthusiastic about the complaints that materiality somehow drains humanity, and so questions the assumptions in the Marxist theory we consider below.

\section{The problems with shopping}

There is also an alternative tradition of critical theory related to consumption. For example, Fromm (1976) notes that societies have become materialistic such that the supreme purpose is to have, and then to have more. Unlike Miller, Fromm observed a resulting lack of care and appreciation for possessions in a society where people throw away things, just to buy anew. For a parallel argument, but from an economic perspective we might also note Scitovsky's (1976) Joyless Economy.

A similar, but even more pessimistic analysis is provided by Marcuse (1964) who discusses consumerism as a form of social control, arguing that individuals are encaged in an illusion of freedom and satisfaction through their consumer engagements. Markets create both new needs and their satisfaction, but with detrimental effects for people and the environment and people have become so preoccupied with shopping, their energy so invested in it, that they are unable to see other ways of living. Marcuse (1964:53) notes: 'if individuals are pre- 
conditioned so that the satisfying goods also include thoughts, feelings, aspirations, why should they wish to think, feel and imagine for themselves?' [our emphasis]. The result, for Marcuse (1966), is that the individual finds ways of 'not knowing' that allow them to enjoy the positive aspects of work and spend lifestyles whilst remaining dominated. As we shall see, Marcuse's (1966) excess repression shares much with the idea of discounting in Script Analysis.

More recently, IIlouz (2007) has argued that in 1960s a growing discontent with the consumer society meant a change in cultural notions of the self, and a movement towards the idea that people who were unhappy or unfulfilled needed therapy. But humanist calls for selfactualization and wellbeing (by the likes of Fromm and Marcuse) created a paradoxical outcome: by contrasting everything to the 'fully self-realized life' (Illouz, 2007:46) a wide array of dysfunctions or unhealthy symptoms were inferred. Yet this 'sick-self' could only be helped with resources from the market that subsequently became more emotional, whilst private intimate lives became cold and dominated by economic principles.

\section{The comforts of problem shopping}

One specific individual dysfunction to have emerged is excess shopping, and before we consider Script Analysis, we should explain how shopaholism is more often understood. As a 'disorder', compulsive shopping was identified over 100 years ago as 'an obtrusive compulsion which is resisted as long as possible, while the performance of the act is accompanied by a feeling of relief' (Krapelin and Diefendorf, 1915). In labeling 'buying maniacs' or 'oniomaniacs', Bleuler (1924) noted that their behavior 'leads to senseless contraction of debts with continuous delay of payment until a catastrophe clears the situation a little'. Yet it's hard to distinguish such dysfunction from Campbell's (1987) description of consumer desire that defines much contemporary shopping, and in the last 5 years the UK's 
consumer debt has risen by $7.35 \%$ to $£ 200 \mathrm{bn}$, and consumer credit has increased by $19 \%$, with some analysts describing the consumer credit market as a risk for economic stability (Inman and Barr, 2017; Quinn, 2017). Risky debt has become normalized in an economy that relies on growth in consumer spending, despite knowledge that it is environmentally unsustainable (see Jackson, 2009).

Nevertheless oniomania remains presented as a rare, debilitating condition (Kearney and Stevens, 2012). As Bauman (2013) notes, a problematic aspect of society (shopping) has been individualised. This changes its moral character from the responsibility of businesses, or government, to the treatment of affected shopaholics by psychologists, despite recognition that the etiology of compulsive buying includes cultural and biographical influences. Compulsive shopping is mainly reported in developed market-based economies, and runs in families (Black, 2007). Having accepted the pleasures of life in the marketplace, consumer societies therefore avoid angst about possible negative effects by constructing them as dysfunctions in a few, i.e. if shopping is a damaging activity, it is (thankfully) only so for a handful of 'ill' people.

Mainstream media also trivializes the issue even as it sensationalizes it by referring to 'retailium extremis' (Svoboda, 2010), or shopaholism (an obvious link to alcoholism, see Kearney and Stevens, 2012), so that the condition may be acknowledged without anxiety, in perhaps the way that most regular drinkers distance themselves from, and so don't associate themselves with, the term alcoholic. If you label an activity as an illness only when done in the most outrageous excess, you make it the concern of just the few, allowing everyone else to carry on with it. Despite the long history of highlighting negative aspects of our consumer society provided by critical theory then, excessive shopping remains marginalized as exceptional, and ironically as a condition that may benefit from psychological interventions. 


\section{Script Analysis and shopping}

If we bring these often contradictory discourses together we are left with a view of shopping as a central and orientating sociology, albeit a potentially troubling one. It has become a source of pleasure, structures relationships, and maintains the purpose of work and leisure, but also represents potential domination, and alienation from oneself and others, to the point that even humanistic complaints and solutions feed into marketplace innovation. We now consider how Script Analysis enables an alternative view of why we shop that integrates the comforting rituals of Miller (2008), the critical purpose of Fromm (1976), or Marcuse (1964, 1966), and the idea of shopping excess.

\section{Biographical scripting}

Along with the widely known PAC model of Parent, Adult and Child ego-states, and their related Games, Script Analysis is a central idea in Transactional Analysis (Berne, 1964) that emerged in San Francisco in the 60s as a new approach to psychotherapy. Berne saw TA as a development of Freud's ideas and methods of helping people (see Barnes, 2007) and interactions between TA and other psychoanalytic traditions remain common. For example, Allan and Allan (1989) see Berne's work as consistent with object relations (which Berne certainly new about) because it deals with internal representations of the self and others. English (1988) also notes connections between the roles within TA scripts and Jung's archetypes, as models from which the child develops patterns of interaction. A further consistency here is the way in which scripts reproduce myths, or fairytales as representations of how lives may unfold (see Berne, 1964, 1972; Karpman, 2011; Stewart and Joines, 2014).

In TA, interactions with others are defined by early experiences and their later reenforcement. Berne (1972) defines a Script as an unconscious life-plan that is made in childhood, and then justified by subsequent events. Scripts carry expectations and options for 
responding to situations, i.e., we experience the world through versions of past experiences, and respond with past reactions, so projecting the past into the future. Script Analysis therefore theorises the internal self and other representations that model how to deal with the world and to what end, as a theory of biographical psychology. Scripts unfold as recurring dramas, with plots and characters, a beginning, middle and an end (Stewart and Joines, 2012) and the whole reinforcement process is captured by Erskine and Zalcman's (1979) as a Racket System. Script-bound individuals become stuck in a system of distorted feelings, thoughts and actions based on script beliefs that result in external and internal displays, behaviours, emotions and fantasies (which can be observed or reported), and reinforcing memories that are evoked to make sense of current behaviours (Erskine and Zalcman, 1979; Stewart and Joines, 2012).

An individual is most likely to hang on to their Racket System where later events and message are reinforcing. As Berne (1964) notes, however, as a transference phenomena scripts may be understood by people and so modified. In this sense, Berne (1964), and later TA analysts, present a project closer to Fromm and later Humanist Psychology, than to Freudian diagnosis and treatment of dysfunction. This also means that the identification of a Shopaholic Script and its associated Racket System can be used by marketplace actors as a reflective tool to understand shopping in society, and indeed this is an opportunity presented by the Shopaholic novels.

A child is subject to the expectations and pressures from parental figures, which in turn incorporate the cultural resources around them (Steiner, 1974). Parental injunctions and attributions therefore inform a script (Steiner, 1974; Stewart and Joines, 2012). Injunctions produce inhibitions in the behaviour of the child, often reflecting anger or unmet desires or needs. They vary in range, intensity, areas of prohibition and malignancy, and can be classified in terms of degree, some having 'third degree' tragic outcomes. Examples of 
injunctions are: ‘don't be happy', 'don’t think', or 'don't grow up'. Injunctions tell a child what he/she must not do. Attributions, on the other hand, tell the child what he/she must do or be remain in the Parental favour, for example 'be cute', 'be quiet', 'be dumb'. In this way, a child learns how to gain strokes, the attention from others that confirms one's existence.

Individuals driven by such scripting must ignore, or 'discount', aspects of reality that are inconsistent with its parameters. As Noriega (2010:200) suggests, discounting comes from 'an unconscious need to understand and give meaning to unresolved issues from the past'. It is therefore consistent with Freud's idea of repression that was used in Marcuse's critique of consumption. People can discount aspects of the self, others, or the situation, ignoring information, the meaning of that information, the ability to solve a problem, or possibilities for different actions, and instead only seeing stimuli, situations, and emotions that confirm their script (Mellor and Schiff, 1975).

\section{Life-scripts and the market}

Berne's (1964) original script was the Alcoholic, but Steiner (1974) later observed that this actually forms a basic joyless script of habitual excess related to deferral. Like all life-scripts, Alcoholic starts with parental injunctions, i.e., things that were said out loud, or actually happened. For example, an injunction like 'You can't drink until you're an adult!' is internalised by the child not only as an existential restriction (you can't), but also as deferral: 'When I'm adult I'll drink'. Adult behaviours are therefore defined by restricting a childhood want (Berne, 1972). A child sees apparent pleasure, but is told they can't have it until some later condition is met. Alcoholic also illustrates the interaction between cultural scripts and life-scripts. Alcohol as an adult domain is culturally determined, like the freedom to take credit and shop without apparent restriction. 
In describing the Alcoholic Script, Berne (1964) further identifies complimentary roles projected from interaction patterns established early in life. These relational dynamics include persecutors willing to castigate, a rescuer such as a doctor, or a relative who is interested in the Alcoholics' drinking habits, and patsies such as bartenders or relatives who extend credit. Berne (1964) explains the Alcoholic Script as an unconscious existential plan to ask others to notice 'how bad I have been' and to 'see if you can stop me', with a denial of responsibility, and the aim of repeated self-castigation. As a life-script, it allows for related Games that pleasurably structure time and relationships. For example, following the routine of drinking excess and misbehaviour, 'Martini' involves conversation about how much and what has been drunk, and 'Morning After' discussions are about the impact on others and how bad the player now feels. Berne (1964) further notes (with some irony) that organizations such as Alcoholic Anonymous can become integral to scripts by facilitating identification of Game behaviours. For example, alcoholics 'drink before breakfast' and 'spend saved money on alcohol'. In this way, scripts become culturally constructed and reinforced.

In line observations by Fromm and Marcuse, and around the same time as Scitovsky (1976) published the Joyless Economy, in Scripts People Live, Steiner (1974:142) further argued that joyless scripts pervaded American society and were exploited by businesses in 'a frantic earning, spending, manufacturing, selling, energy-consuming pace which eats up our resources'. For Steiner (1974:142), shopping represented a too common life-script as he notes that 'having a new car, washing machine, or wardrobe feels good, and, just like drugs, buying is a ready avenue to pleasure [...] The consumer's 'morning after' hangover, the damage done by his excesses, in his bills, to which he becomes a slave'. Further, Steiner (1974:131-132) suggested that a consumer society is founded on discounting: 'we are fully prepared not only to be liars but to accept lies from others. It's a small wonder that people passively accept the 
lies of their elected officials, advertisers, and the media; their training to do so is relentless from early childhood on'.

Steiner's (1974) consumerist revision to Alcoholic is the Plastic Woman, the script of someone who gets existential strokes by buying 'bright jewellery, platform heels, foxy clothes, intriguing perfumes and dramatic make-up' (Steiner, 1974:179-180). Although shopping may remain a gendered practice (Martens, 2016), the sexism in Steiner's language is best understood as a product of the time and place he was writing. We might equally consider the Plastic Man in the behaviour of the metrosexual, hipster, or any other shopping by male consumers subjected to consumer scripting. Steiner (1974) notes that consumers (who we might refer to as Plastic People), feel powerful when they can buy what they want, but at the same time have little power outside the store, as they can't buy what they really want, which is the intimacy denied by an over-adaptation to interact with others via shopping (also see Böhm and Batta's, 2010, discussion of Lacan). The injunctions and attributions that drive this script are 'Don't get old', 'Don't be yourself', or 'Be cute'. Plastic Person is therefore a critique of shopping as identity work. Berne (1972) considered such 'until scripts' as a tragic deferral of life through a myth of immortality that means always hoping for something in the future, captured through his interpretation of Sleeping Beauty.

\section{Scripts, fairy tales, and literary texts}

This brings us to how TA recognises the importance of fairy tales. Fairy tales help children to make sense of their place in reality, and their expected relationships with others, i.e., they help children to understand their script (Berne, 1972; Cornell, 1988; Le Guernic, 2004).

The idea that we can learn from fiction is also not new in marketing theory. Levy (1981) notes the value to marketing theorists of insights about human nature provided by literary texts, then compares this to the stories consumers tell about brands. Belk (1986:26) 
also notes that 'art can be a useful way of generating knowledge... [and] may be seen to provide an attractive alternative to more traditional 'scientific' means of consumer research'. And Stern (1995), perhaps more than anyone (see Brown et al., 2013), has argued for textual analysis as a basis for market insights. The 'literary criticism' approach can be applied to both marketing texts, and texts that include references to consumer culture. Hence, Patterson and Brown (2005) advise marketing theory by examining Bridget Jones's Diary and Fight Club and earlier Brown (1995) considered compulsive consumption, gift giving and shopper apathy through Judith Krantz's Scruples. In analysing various Titanic texts, Brown et al. (2013) also suggest that the myth permits catharsis of the ambiguity and anxiety around death, allowing for the development of skills to deal with one's own mortality. Myths therefore allow consumers a reflective place, removed from painful reality (Brown et al., 2013). Critiques of consumption also find their way into fiction, for example in The Great Gatsby and Death of a Salesman reviewed by Patsiaouras et al. (2016), and in Ballard's Super-Cannes (see Fitchett, 2002). We could add Ballard's High-Rise (1975), Easton Ellis's American Psycho (1991), Beigbeder's 99 Francs (2002), and Palahniuk's Fight Club (2005) to this list (see Brown, 1995, for a separate, but overlapping list). Each novel connects consumption with violence and the ultimate fall into madness of the central characters, or what Berne (1964) might describe as 'third degree scripts'. However, Brown (1995) also argues that rather than focusing on elite literary artefacts, the symptoms of dysfunction in society are made more 'visible' in popular texts as they better resonate with our daily lives. This is closer to how Berne (1972) understood fairy tales: not as grand morality tales, but as of personal relevance to individuals' scripts. Although the child might identify with the Sleeping Beauty story, as an adult they may confirm that script through the Confessions of a Shopaholic.

Script Analysis suggests that people unconsciously orientate to the narratives that reflect their own injunctions and attributions. For example, Berne (1972:59) analyses Little 
Red Riding Hood, Sleeping Beauty and Cinderella, arguing that fairy tales inform 'the first and most archaic version of the script'. Later English (1988) describes fairy tales as 'the threads of a rug into which one weaves one's story'. In Sleeping Beauty, Berne interprets the 'magic sleep' as an illusion of eternal youthfulness, hence consolidating a 'don't grow up' script. For Berne (1972), the tragedy is that although Beauty doesn't age as she sleeps, in reality people do. It's worth noting that in the Shopaholic novels, Kinsella tells us that Becky Bloomwood compares herself to Sleeping Beauty and for Berne, the stories we most identify with reveal much about our script (Berne, 1972; Karpman, 2011).

Radner (2011) argues that chick-lit (along with 'girly' films) tells us about collective drives, conscious and unconscious desires, and audiences' fears, i.e., they relate to possible cultural scripts. Specifically, Radner (2011) identifies the establishment of the ideal of the single girl from the 1960s onwards who defines her identity through shopping, and who aspires to be financially independent, glamorous, and adored by men, in films such as Pretty Woman, Legally Blonde, The Devil Wears Prada, Sex and the City: The Movie, and Ally McBeal, and books such as Kinsella's Shopaholic series. Whilst this ideal of the single girl promised empowerment and emancipation from patriarchal constructions of women around marriage or maternity (Radner, 2011), the void left was filled with the illusion that it is through shopping that one is constantly able to culture the self and the body. Similar to Steiner's Plastic Woman, this led to a belief that shopping is a key source of fulfillment and purpose in one's life. Becky Bloomwood therefore invites the fairy tale of the single female, emancipated through her shopping expertise, to be incorporated into readers biographical psychology, reinforcing that it is only though shopping that one will one day be happy. Kinsella brings the Shopaholic Script into the lived experience of ordinary people, capturing the pleasures and intimacies of shopping in addition to more dramatic outcomes. 
Our approach to the text is similar to Patsiaouras et al. (2016) who apply a psychoanalytic reading to The Great Gatsby and Death of a Salesman to generate theory. We draw from both the novels, and paratextual material such as commentary on the book, interviews with the author, reviews from readers, and the film adaptation. In addition to including reader's identification with the text, a benefit of this approach is the ability to examine biographical aspects the life and relationships of a fictional shopper, something that would be both impractical using real people and open up complex issues relating to "wild analysis' (Holmes, 2012). In applying Script Analysis, we reveal cultural forms of recognisable life-scripts with the relational dynamics suggested in Berne's original Alcoholic and Steiner's later Plastic Woman (Berne, 1972; Steiner, 1974; Stewart and Joines, 2012). We can't talk to Becky as a TA therapist might, but we can use the techniques established by TA practitioners to examine the text. In particular, we pay close attention to Becky's behaviours, her narrated emotional experiences, and the fantasies she reports. We can also note reinforcing memories, the events in her life that prompt shopping, and the messages given by others.

\section{Becky Bloomwood's Script}

British novelist Madeleine Wickham, also known by the pen name Sophie Kinsella, created the fictional character of Becky Bloomwood, a financial journalist who finds herself in debt through excessive shopping. Wickham mentions that in creating Becky's character she was inspired by her own experience:

I was out shopping and had a sudden image of a girl opening her Visa bill. I could just imagine all those emotions you go through - the shock, the anger, the denial... I could instantly see the funny side of shopping and I couldn't believe that nobody had written 
about shopping before. I almost raced home to start writing this character and her adventures and the way we all think when we shop (Wickham, on her website)

She also specifically recognises the family members who apparently taught her to shop (and so must take some credit for the narrative) in the acknowledgements of the first book.

Becky has now appeared in 8 books that have been translated into 30 languages. The first two books Confessions of a Shopaholic (also published as The Secret Dreamworld of a Shopaholic) and Shopaholic Abroad were also adapted into a film titled Confessions of a Shopaholic. Despite the film's weak performance at the box office (attributed to poor timing following the financial crisis of 2008, see Colman, 2009), later books have continued the successful franchise with Sophie Kinsella's 440,000 Facebook followers still calling for more.

This is popular fiction, a 'holiday read', and 'chick-lit'. Excess shopping, it seems, is something we may chuckle over whilst laying on a beach. Yet, in dealing with the shopaholic in a frivolous and even superficial way, Kinsella also presents the normalisation of overconsumption as reasonable and even light-hearted subject matter. Confessions of a Shopaholic isn't a morality tale about the shallow and superficial nature of Becky's life and her descent into oblivion (cf., American Psycho, or The Great Gatsby), and nor does it offer much promise of her growth and redemption. The apparently happy ending of the first book makes it clear that there is much more shopping to come, and indeed we see Becky's shopping excess continue in her wedding, house buying, and the birth of her first child.

In presenting the relationships people have with and through shopping, Kinsella offers a reader a fictionalised version of their own (and possibly her own) relationship with shopping, where things get out of hand, but where there is never serious risk. There are over 1,200 Amazon reviews that capture both readers' vicarious pleasure as Becky buys designer goods, and their frustration at her repeated deceits in the interests of shopping. One reviewer 
notes: 'Initially I was getting disgusted with the main character, then I began to see myself in her actions', another reports, 'You spend half of the book wanting to slap the main character and half of it cheering her on', and another reflects, 'Some reviews talk this book down because the financial ineptitude hits close to home'. A reviewer sums up:

It gets frustrating to know this person is real! There are many women out there like this! Started reading the series but after the second book $\sim$ I don't want to know Becky anymore $\sim$ she needs help, grow up and become a responsible human being!

The ambivalence in academic readings of the shopping experience are therefore echoed by Kinsella fans, and indeed in a Guardian interview Kinsella herself notes the dilemma facing her readers:

... the first book opens with a bank saying, 'Why not take out an overdraft?' and then saying, 'Why haven't you paid back your overdraft, you evil person?' And actually, I laugh when I hear the politicians now saying: 'We've got to cut back - but we've got to make more money.' Well, that's Becky Bloomwood's mantra... Her dilemma is the country's dilemma (Aikenhead, 2012).

Kinsella has a PPE degree from Oxford and is therefore likely aware of neo-liberal structures and their critique. Indeed, she makes several references to the later, not least through Becky's adventures with her sister, a committed environmentalist. For example, in an interaction between Becky's sister and her parents' neighbour in Shopaholic and Baby: 
Jess and Tom are having a conversation, when Jess notices the book he is holding, and asks: 'Is that The Consumer Society: Myths and Structures?' 'Yeah, have you read it' 'No, but I've read another of Baudrillard's works, The Systems of Objects'

Despite Becky's many opportunities to give up excessive shopping, she does not. Kinsella's witty narration of Becky's seemingly endless misadventures in consumption reflect underlying consumer scripting in society, and our determination to make light of, or to discount its negative consequences. Becky shops to structure time, to celebrate good news, to comfort herself following negative experiences, when she is bored, when she has free time, and even when she doesn't. She dislikes her job, but sees it as a way to fund shopping. She takes an extra part time job in a shop to pay of her debts, but loses it almost immediately when she gets into an argument with a customer over the last sale pair of jeans Becky wants for herself. Later, she tries to get better-paid jobs specifically so that she can shop more. Apparently oblivious to the skills that might be required (and that she doesn't have), she is prepared to lie on job applications.

Even her romantic life is seen in terms of shopping. After finding out that her roommate has a cousin who is the tenth richest bachelor in the UK, she undertakes to date him despite confessing to no attraction, whilst daydreaming of the shopping possibilities his wealth would afford. Her more serious love interest is also understood in terms of how he might facilitate her desire to shop, and indeed their first date is a shopping trip. Becky's life progresses because of shopping, yet shopping is also the source of her failures.

Becky's adventures reveal shopping as an over-adaptation that makes it the 'go to' practice to progress life, define relationships, and fulfill goals. She learnt this from an early age, but in reaching for a shopping script, her adult autonomy is rejected. The Shopaholic series presents readers with a fairytale of shopping not because it's a warning of consumer 
excess with violent ends, but because it contains familiar patterning in an accessible, humorous form that allows us to recognise and laugh at our own shopping scripts. What we also see for Becky is evidence of script reinforcement at each stage in her life that the books deal with: growing up, working, relationships, children and, no doubt middle-age, if the franchise continues.

We now want to highlight three aspects of the shopping script that are revealed by Confessions of a Shopaholic: Becky's injunctions, attributions and discounting; Becky's script helpers who ensure drama, and; the joylessness of her script.

\section{Becky's injunctions, attributions and discounting}

That Becky is defined by her shopping is apparent to those around her. For example, both Luke (love interest) and Suze (housemate) recognise Becky for her shopping skills. Luke asks her to help him buy something as the context for their first 'date' (and before that lends her money to buy something). Suze frequently waits for Becky's return to their shared flat in the hope she has bought something. This is a Plastic Person trait, being valued by others for the ability to shop. When Becky visits her parents, we come to understand that her mother also interacts with Becky through shopping. For example:

Mum is sitting at the wrought iron garden table leafing through a Past Times catalogue... "Becky agrees with me don't you darling?" says mum and points to a page of past times, full of 1930 s reproduction jewellery, "Lovely cardigan", she adds.

When they talk, they are often shopping. They visit a craft fair and Becky observes: 
Mum is really happy, she's found a pair of candlesticks for her collection. She's got collections of candlesticks, toast racks, pottery jugs, glass animals, embroidered samplers...

Becky notes her father's disapprove of her mother's shopping, but also that her shopping is what he pays most attention to. Like Becky, her mother structures both time and her relationships through shopping. Father also interacts most with Becky when she is in trouble over her finances following excesses shopping, advising her (with satisfaction) that she must either 'Cut back' or 'Make more money'. When Becky dreams of her wedding to Tarquin, she imagines: 'My head is filled with a happy vision of our wedding day. Me in some wonderful designer dress; my mum and dad looking on proudly. No more money troubles. Ever'. Indeed, throughout the books, Becky narrates her internal fantasies where the recognition by others is associated with specific goods. For example, when she buys a green scarf, she fantasies that by wearing it she will become known as 'the girl in the green scarf'.

Brands 'talk' to Becky (in the film they literally come to life) as if they were a Nurturing Parent similar to her mother. Banks and credit companies, on the other hand, take on the role of Disciplining Parent. Of course, the finance companies want Becky to shop too, just like her father, as otherwise they would have no reason to interact with her. For Becky the market therefore represents her relationship with her parents. Father encourages shopping in the mother, and mother duly conforms. Just as Berne's (1964) notes in patterns of Parental injunctions and attributions - father tells her what to be, and mother shows her how - we see how the banks tell Becky (and all consumers) what to be (in debt) and the consumer brands show them how.

Related to the injunctions and attributions that persist in how Becky experiences the world are a series of discounts. For example, she notes that her mum buys things she doesn't 
need, even as she is in trouble for the same behaviour: 'She's always buying new stuff for the kitchen...we've already had three new rubbish bins this year. I mean what a waste of money'.

She also disregards the extent of her debt, or how it might be paid back, ignoring or disposing of bills and then forgetting that she has done so, just as she seems unable to remember what she has bought, effectively discounting the implications of purchases and more specifically her ability to control her actions. For example, when she buys a self-help book on saving money, she is highly selective of how she reads it, first noting:

... and really it's not my fault. I've merely been succumbing to the Western drag of materialism-which you have to have the strength of elephants to resist. At least that's what it says in my new book.

She then selectively reads the first instruction in the book that suggests you should record details of your shopping: 'and the best thing is, you have to start out by going shopping'. Here the 'reality' of the advice is ignored in favour of a reading that perpetuates the shopping script, and associated pleasures.

Further discounts include ignoring the odds of winning the lottery, or of getting a job in finance that she isn't qualified for. In both cases, her experience as a financial journalist provides information that should allow her to recognise reality, but she doesn't. It's also clear that despite her own humorous fabrications and manipulations of others, she is apparently unable to recognise deception in sales promotions, branding messages and retail offers. Becky even ignores her own romantic feelings towards Luke and her lack of feelings for millionaire Tarquin in favour of her ability to continue shopping. Behind the romantic comedy is a character that struggles to form meaningful relationships because she is unable to see them in terms other than how they support her shopping script. In the film she states: 'You see a man 
will never love you or treat you as well as a store. If a man doesn't fit, you can't exchange him seven days later for a gorgeous cashmere sweater'.

Discounting is also apparent in the rhetorical questions directed to reader where Becky notes things like: 'I just had to, didn't I?', 'It would be a crime not to, wouldn’t it?', or 'It couldn't hurt, could it?'. As Steiner (1974) notes, a clear sign of discounting is where an individual states that there was no other option. Reviewer irritation at this literary device recognises that when Becky makes these claims she is often 'playing dumb'. The purpose of discounting is therefore to allow for shopping. Becky discounts the fact that shopping brings no lasting pleasure, and then further discounts anything than might prevent such or reveal such behaviour.

\section{Becky's script-helpers}

Becky experiences others through roles that further a shopping script. The bank manager, bosses and store staff (when payments fail), are experienced as persecutors, denying Becky what she wants and justifying both her manipulation of others and continued determination to shop. Their negative framing is based on the risk they pose to Becky's shopping. Her boss is even vilified for asking her to work when she 'needs' to get to a shop before closing time. Here, we see how discounting produces experiences of victimhood where there isn't any. Much of the reader's knowledge of these persecutors is through the letters they write, including often-contradictory warnings about late payments, then offers of more credit, but ultimately denial of funds. As Becky describes them: 'They said I was a valued customer, but now they send me hate mail'.

Enablers, on the other hand, are seen in parents, in love-interest Luke (lending money sets up their relationship), in-store staff (offering to hold goods when Becky is short of money), and especially in Suze (help with money, help with relationships, help with work). 
Despite repeated lies and misbehaviour, almost everyone forgives Becky though (even Smith, the bank manager), and so allow her to continue her script. As an Amazon reviewer puts it: 'Becky is not a perfect person (and neither is anyone else), some of her ideas are a little harebrained, and her friends and family are overwhelmingly forgiving'. Becky's misbehaviour often gains her sympathy. Even her parents' neighbours (who she badly lets down) forgive her and offer to help.

These rescuers have their own ulterior motives and hence projections onto Becky, so gaining satisfaction by allowing Becky to continue her shopping. Suze (Becky's housemate) in particular allows for further shopping because she actually enjoys the acknowledgment she gets for helping. For example, at one point when Becky is asked to pay a bill she notes:

I look up to see Suze tearing up the check... 'pay me back when you're in the black', she says firmly. 'Thanks, Suze,' I say...as I give her a big hug I can feel tears jumping into my eyes. Suze has got to be the best friend I've ever had.

Suze and others actively support Becky's shopping. On several occasions she is waiting for Becky to return from a shopping trip, declaring: 'Show me, show me, show me!' she comes over and starts tugging at the strings of the carrier', and on another occasion Becky explains: 'I open the door to the flat and Suze comes rushing up, like a puppy. 'What did you get?' she cries'. In return, Becky justifies shopping for Suzy. Having tried not to purchase anything to save money, Becky explains:

I did incredibly well over the next couple of days. The only things I buy are a really nice chrome flask to take coffee into the office (and some nice coffee beans and an electric grinder). And some flowers and Champaign for Suze's birthday. But I'm 
allowed to get those, because, as David E Barton [author of her self-help book] says, you must treasure your friends.

Brands, store staff, financial institutions, Suze, and her mother all act as patsies when needed. Becky's mother encourages shopping whenever they meet. Suze forgets Becky's debt to allow shopping, encourages shopping and generally plays along with misbehaviour. Store cards constantly offer to lend more. The bank tolerates extended late payments, missed meetings and being overdrawn. Store staff, and especially brand messages, explicitly reward and encourage consumption, especially in seductive sale offers.

\section{Becky's joylessness}

It was Becky's dream to shop. Her first lines in the first book and the movie are:

When I was a little girl... I looked into shop windows, I saw another world. A dreamy world full of perfect things. A world where grown-up girls got what they wanted. They were beautiful. Like fairies or princesses. They didn't even need any money, they had magic cards.

Despite apparently fulfilling this fantasy, however, Becky experiences no lasting satisfaction from the things she buys. Each item is quickly forgotten (at one point she finds clothes hidden in her room that she has never worn). Despite the considerable support that Becky apparently gets from friends and family, and repeated romantic interest, when she reflects on her final miserable state her conclusion is: 'If everyone could just wear new clothes every day, I reckon depression wouldn't exist anymore'. 
Yet Becky gets regular doses of guilt following excess shopping, and the lies she tells in order to cover it up. Shopping provides an existential payoff when things are bought, then again when guilt is experienced, then once more when things spiral out of control and friends and relatives forgive her. After one shopping frenzy she laments:

I wake up early feeling rather hollow inside [...] I know I spent too much money on Saturday. I know I shouldn't have bought two pairs of boots. I know I shouldn't have bought that purple dress...

This is almost the same description she gives after waking up with a hangover. Yet, with each setback the cycle is repeated, so that having been fired from a part time job in a shop that she took to pay of some of her debt, Becky reflects:

No job, no money, no [store] discount... still at least I've got twenty quid... I'll buy myself a nice cappuccino and a chocolate brownie. And a couple of magazines. And maybe something from Accessorise.

Other aspects of the joyless script include the persistent fear of her bank manager and boss, and a lack of career progression (because she doesn't take her job seriously). The absence of joy through authentic relationships with other people is also expressed literally in her description of eventually dumping a boyfriend who refuses to have sex with her, but her rejection of men who want to (even one who would allow endless shopping). Things that might bring lasting pleasure (satisfaction from work, a loving relationship, having her own home) are persistently undermined in preference for shopping that brings anxiety and distress 
along with immediate pleasure and the certainty of drama that structures time and relationships with others.

\section{Discussion: the Shopping Script and Racket System}

Despite the enduring popularity of TA (see Molesworth et al., 2017), Script Analysis can seem deterministic and reductionist, dismissing free will, and understating the significance of societal structures and cultural practices (Cornell, 1988; English, 1988; Mazzetti, 2010). We might now view the hyperbolic claims for Scripts used by both Berne (1964) and Steiner (1974) as a necessary rhetorical approach to get people to reflect on scripting. For example, the claim that life-scripts are 'done and dusted' in the first few years of life (Berne, 1974; Steiner, 1974) can be read as an invitation to explore early relationships to unpack possible limiting qualities in current habits. For Cornell (1988) however, there remains a need to reconsider scripts in light of newer developmental theories, especially empirical observations that a child's development carries more plasticity that script theory originally suggested. English (1988) attempts to overcome such limitations by redefining scripts as 'survival conclusions', that may be overly strong and unproductive in those who don't distinguish between useful conclusions (about the world) and dysfunctional ones that were not corrected through experience. The implication is a need to consider that scripting happens throughout life, often reinforced, but potentially challenged, by life's developmental stages. This also means that a Racket System needs to acknowledge the potential for both script-reinforcing and script-challenging events and messages. For Becky we see how her adaptation to shopping is all too often reinforced.

Mazzetti (2010) also suggests that although Berne recognised the significance different cultures, the need to present TA as a universal theory meant that cultural influences were underplayed. Mazzetti (2010) notes that where culture is ignored, what seems like 
autonomy from scripts may actually be adaptation. For example, Berne's (1964) 'winner script' represents cultural ideals in the US in the 60 s (captaining the football team and 'getting the girl'). For Mazzetti then, scripts always also represent the culture that sustains them.

Like other psychoanalytic theory derived from therapeutic practice, Script Analysis may also overemphasise individual dysfunction over societal structures. For Cornell (1988) well people adapt; the ill stick to script, and so there is a risk that we overstate Becky's dysfunction and downplay her positive emotional experiences. Indeed there is little doubt that Becky is a skillful consumer. English (1988) explains that Berne wanted to account for the problem that despite therapy, people often stick with Games, concluding that when this happens there is a 'deeper' script at work. We can compare such pessimism with even less optimistic analysis, for example Fromm's idea in Sane Society (1955) that a whole society can be sick, or Marcuse's (1964) surplus of repression. Hence a 'sick' society invites dysfunctional cultural scripts and we might conclude that Becky, and those who recognise themselves in her shopping, are actually well-adapted to current social and economic structures.

Since the early work of Berne and Steiner, there has therefore been significant reflection on scripts within the TA community consistent with Berne's own wish that theory that doesn't produce results should be modified. Indeed, Berne's contradictory ideas about scripts highlight an unfinished project (Cornell, 1988; English, 1988; Mazzetti, 2010). For Cornell (1988), Script Analysis retains value as a set of internal solutions to life's problems that are all too readily deployed, rather than a final and fixed destiny. English (1988) also notes that scripts should be thought of as determining rather than determined, and following Mazzetti's (2010) recommendation, we have paid more attention to the cultural aspects of ongoing scripting. 
Berne's Alcoholic (1964) and Steiner's Plastic Person (1974) therefore direct us to a contemporary shopping script, captured by Confessions of a Shopaholic, a fairy tale of a life built around shopping that is enjoyed by millions. This allows us to recognise shopping as an over-adaptation, created by parental injunctions and attributions then reinforced throughout life. Key in our analysis is that the scripted shopper understands their existence, structures time, and makes sense of relationships, through shopping. In exploring Becky's life, inner world, relationships, and repeating shopping dramas, Confessions of a Shopaholic illustrates how such scripting works and even if our own lives are not quite so scripted we might recognise (and enjoy) the Games that shopping makes possible (also see Molesworth et al., 2017).

In theorising the Shopaholic Script, we draw from Erskine and Zalcman's (1979) Racket System (also developed in Stewart and Joines, 2012). Here, the impact of a script is seen in displays that include observable behaviour, reported internal experiences, and fantasies, or syntonic imaginings that reinforce a script in the absence of completed experiences. The Racket System also considers reinforcing memories (injunctions and attributions) and following the need to consider culture, we include reinforcing events and messages here too (see Figure 1).

[Figure 1 here]

\section{Displays: Observable behaviour, internal processes, and fantasies}

Becky represents the ways in which shopping structures time and relationships through Games. A relative (Becky's father) or friend (Suze) plays rescuer, or patsy, along with store cards and banks willing to extend credit, and reward shopping behaviours with offers, discounts and loyalty schemes. Patsies may turn persecutor when the script demands it (also 
see Karpman's Drama Triangle, 2011) as is the case with lenders offering credit, then demanding payment. 'Morning After' becomes 'Overdraft', as Becky complains about how much she spent and how difficult her finances now are, and 'Martini' becomes 'Look What I Got', the pastime of showing off what was bought. These Games are repeated throughout the Shopaholic novels.

Becky also narrates her internal experiences, describing her longing, aching, 'Do anything to get them' feelings towards specific goods. Yet the result is not, as Campbell (1987) theorises, simply the loss of desire following purchase, but experiences of regret that result in her seeking the support of family and friends (which she always achieves). Script Analysis therefore suggests a relational purpose in cycles of desire based on the need for strokes that are achieved when things are bought, and again when this results in problems.

In the absence of achieving recognition from others, Becky imagines them. We see this in her imagined wedding (recognised for what she wears), and in the way she imagines becoming known for wearing a particular scarf, or dress (or any other desirable item). Here the fantasy is syntonic. It confirms to Becky that one-day she will buy the thing that ensures endless existential strokes, but discounts the possibility that strokes may come from elsewhere.

The Scripted Shopaholic also explains how a more general Joyless life position is enacted through consumption as an unconscious plan to ask others to notice 'How bad I have been' and to 'See if you can stop me' with the aim of self-castigation. It is progressed through events that either present a provocation, followed by accusation, or indulgence followed by anger or disappointment, leading to guilt, powerlessness, and ultimately forgiveness. Throughout Confessions of a Shopaholic the key events of Becky's life unfold this way. Becky lies about shopping, shops to excess, or fails to do other things because of shopping. Each time she does there is a drama, followed by forgiveness and the enabling of another 
similar cycle. Characteristic of the drama is the existential acknowledgement of Becky through what she buys, at the same time as contradictory castigation for over-spending. She is both valued as a shopper, and blamed for shopping too much. We see something very similar in the BBC's Shop Well for Less reality show where participants invite the hosts to help them spend less, never entirely achieve this, but enjoying a review of their excess along the way.

The Shopaholic Script allows psychological dependency on consumer goods, a lifegoal, and a way to avoid responsibility and intimacy. Script Analysis therefore allows for a reexamination of how shopping structures time and relationships that is sympathetic to Miller's (2008) general observations about material goods and relationships, but maintains critical observations about our consumer society (Fromm, 1976, or Marcuse, 1964, 1966).

\section{Reinforcement: memories, events, and messages}

Becky's reinforcing memories are revealed when she is with her parents. She notes her mother's tendency to shop to excess, yet discounts her own similar behaviour. Readers are invited to recognise that she is just like her mother, and indeed the two mostly exchange strokes whilst shopping, reinforcing each others' scripts. Her father on the other hand, pays most attention to her mother after she has shopped, even if this attention may be negative, and engages most with Becky when her shopping has led to problems.

However, the novels also pay attention to the reinforcing events and messages from the market. Each stage in Becky's life is accompanied by the need to shop, and is a context for a novel in the series. Jobs and romantic dates require new clothes, weddings require complex purchases that fill a whole book, children too, and new houses. Each significant lifeevent is understood through shopping excess, anchoring Becky's script. Like Miller's (2008) rejection of the idea that it's the material things themselves that alienate the contemporary consumer, Script Analysis does not place the blame on shopping directly, but rather the ways 
in which consumers' biographical psychology leads them to interact in specific ways using the market as a resource. Script Analysis does, however, recognise the role of marketing in anchoring attributions and injunctions. We therefore see both cultural rules for shopping reinforced by brand injunctions, for example: 'Just do it' (Nike), 'Make the most of now' (Vodafone), buy things, 'Because You're Worth It' (L'Oréal), and that although 'There are some things money can't buy. For everything else, there's MasterCard'. Such messages are themselves determined by an organisational script and, as Mihailovich and Mihailovich (2004) articulate, these dominant scripts are legitimised through capitalism. Hence, making a profit, advertising and selling, as well as shopping, having the latest, and taking loans, become script-parts and roles for all actors in the marketplace that are reinforced throughout life, and are the basis of relational dynamics.

Becky's relationship with the market mirrors her relationship with her parents, and her parents' relationship with each other. Like her father, financial institutions play the primary role of enabler, advisor and potential discipliner. They enable continued shopping, whilst castigating Becky for overspending. Like her mother, brands also play a part an encouraging parental voice. Becky's father is seen to complain about her mother's spending, whilst providing the resources for her to do so. This dynamic is internalised by Becky and projected onto marketplace relationships. She has learnt a script that tells her who to be (from her father) and how to be (from her mother) (see Berne, 1972) and finds comforting existential similarity in the marketplace.

\section{Script Beliefs and Feelings}

The strength of such scripting can be recognised in the repeated discounting necessary to accept market messages without ridiculing them. Becky persistently ignores significant aspects of reality (in sales promotions and advertising, as well as the warnings of her 
precarious financial position). She also discounts both her own ability (as a financial journalist), and the affection of others (especially love interests). Becky's scripting means she is unable to imagine a life outside the shopping-based dramas she creates.

The Scripted Shopaholic therefore maintains a position that denies Intimacy, consistent with the narrative that people may shop to compensate for emptiness (Marcuse, 1964; Shankar et al., 2006; Illouz, 2007). As a post-psychoanalytic approach, the Shopaholic Script explains this as a compulsion to re-experience the patterned emotions that were learnt from early injunctions and attributions in the presence of re-enforcing messages. The temporary liberation from stress through shopping, and then the experience of post-purchase anxiety, suggests that Scripted Shopaholics are 'trapped' in an endless circle of wanting goods, doing everything to buy them, but with very little lasting happiness, not because the goods themselves strip them of their humanity (again see Miller, 2008, 2010), but because such individuals are unable to form relationships in ways that don't reproduce this script. Becky imagines she is most like Sleeping Beauty, waiting for love, recognition, and a happy life, and believing that it is through shopping that this may be achieved.

The internal psychological payoffs that represent repressed feelings are rebellion and a satisfaction of craving (Becky can buy without taking responsibility for her actions), but also self-castigation and reassurance (her repeated apologies, and the comfort of others that results). The external psychological payoffs, however, are an avoidance of intimacy, with romantic partners in particular. Becky's social relations are defined by alternating encouraging, admonishing and caring transactions as she confirms to herself that 'Everyone wants to deprive me' (see Berne's original description of the script, 1964), most obvious in store staff (when there is no credit on cards), her boss at Zara (when she is fired for upsetting a customer), and her bank manager, Mr Smith (who is presented to her parents as a stalker). 


\section{Freedom from the Shopaholic Script?}

We might qualify all this by noting that on the surface Becky and her readers actually have a lot of fun. These books are loaded with humour rather than pathos. Joylessness therefore describes Becky's failure to see and act beyond her script rather than her phenomenological experience of shopping.

As we introduced Confessions of a Shopaholic we noted an ambivalence in readers comments that mirrors the theoretical ambivalence toward shopping. Kinsella herself seems to recognise 'gallows' humour in the book series (see Aitkenhead interview, 2012) as an easy read that confirms the script in many, but that might prompt concerns in at least some readers who start to feel discomfort about Becky's ways of solving problems. It's possible that in a few this discomfort might lead them to question their own shopping, but for Berne (1964, 1972) such easy transformation is unlikely as a script maintains pleasure from reliable strokes - existential survival conclusions as English (1988) describes them - that, if discarded, create anxiety about how to structure time and what to say to others. Both Campos $(2014,2015)$, and Mihailovich and Mihailovich (2004) also note that simply refusing dominant cultural scripts results in the existential anxieties of 'what to do'. Not surprisingly then, the ambivalence of readers is more likely to result in rejecting Becky Bloomwood than in abandoning shopping. If such a shopping script is accepted as dysfunctional, we therefore need to consider freedom from the script (Steiner, 1974); alternative scripts that give purpose to life that don't always require shopping. This starts with awareness of the script, then by tracing injunctions and attributions to better understand discounting, as we have done above for Becky. To achieve autonomy then requires spontaneity (to take new actions, to solve problems, and accept the risk that come from abandoning a script), and intimacy (to see and accept others without the pre-understanding that scripts dictate) (Steiner, 1974; Stewart and Joines, 2012). 
This does not mean giving up shopping itself which, as Miller (1998) and others note, has positive social roles, but rather recognising and breaking away from the script presented in Sophie Wickham's books. Because Confessions of a Shopaholic is a fiction, the conclusion actually captures this process with an ease that TA theorists consider unlikely in practice. Following a final dramatic failure in Becky's finances and a retreat to the parental home she seems to break her script, suddenly recognising knowledge and skills she never knew she had, as well as a love in Luke she didn't think possible. Finally she finds joy, is able to solve problems, take responsibility, and experience intimacy. Yet, of course, this lasts only as long as the opening chapter of the sequel.

\section{Conclusion}

In applying Script Analysis to shopping we are not directly challenging the dysfunction of oniomania (Black, 2007; Svoboda, 2010; Kearney and Stevens, 2012), but rather expanding the range of market activity that it represents. As a life-script, the Scripted Shopaholic represents a behavioral and relational pattern that is characteristic of our consumer culture. Of course individual scripts vary and the Scripted Shopaholic is not the only path a consumer's life might take. As a fairy tale though, Kinsella's books capture one form of consumer scripting in a way that many readers identify with. We hope our use of Script Analysis and our conceptualisation of a Racket System challenges researchers to further explore aspects of marketplace scripts and relational dynamics in both aesthetic media and everyday practice.

We have also illustrated how injunctions and attributions script consumers, as well as the various discounts necessary to maintain this way of thinking. This presents the possibility of freedom from dysfunctional aspects of shopping scripts. Consistent with the project of Script Analysis, we therefore encourage marketing academics, practitioners, and consumers 
themselves to identify their own script, the injunctions and attribution that got them there and keep them there, and the discounting they demand.

\section{References}

Aitkenhead, D (2012) 'Sophie Kinsella: You can be highly intelligent - and also ditzy and klutzy' The Guardian. URL (consulted June 2018)

https://www.theguardian.com/books/2012/feb/12/sophie-kinsella-highly-intelligent-ditzyklutzy

Arnold, M.J. and Reynolds, K.E. (2003) 'Hedonic shopping motivations', Journal of Retailing 79(2): 77-95.

Bauman, Z. (2013) The Individualized Society. London: John Wiley \& Sons.

Baumeister, R.F. (2002) 'Yielding to temptation: Self-control failure, impulsive purchasing, and consumer behavior', Journal of consumer Research 28(4): 670-676.

Belk, R.W. (1966) Art versus science as ways of generating knowledge about materialism. In Perspectives on methodology in consumer research (pp. 3-36). Springer New York.

Berne, E. (1964) Games People Play: The psychology of human relationships. London: Penguin.

Berne, E. (1972) What do you do after you say hello. The psychology of human destiny. New York: Grove.

Black, D.W. (2007) 'A review of compulsive buying disorder', World Psychiatry 6(1): 14-18.

Bleuler, E. (1924) Textbook of psychiatry. Oxford, England: Macmillan.

Böhm, S. and Batta, A. (2010) 'Just doing it: enjoying commodity fetishism with Lacan’, Organization 17(3): 345-361.

Brown, S. (1995) 'Sex'n'shopping: a 'Novel' approach to consumer research', Journal of Marketing Management 11(8): 769-783. 
Campbell, C. (1987) The romantic ethic and the spirit of modern consumerism.

WritersPrintShop: New York.

Campos, L.P. (2014) ‘A Transactional Analytic View of War and Peace', Transactional Analysis Journal 44(1): 68-79.

Campos, L.P. (2015) ‘Cultural Scripting for Forever Wars', Transactional Analysis Journal 45(4): 276-88.

Chatzidakis, A. (2015) 'Guilt and ethical choice in consumption: A psychoanalytic perspective', Marketing Theory 15(1): 79-93.

Cluley, R. (2015) 'Consumption and repression’, Marketing Theory 15(3): 365-379.

Cluley, R. and Desmond, J. (2015). 'Why psychoanalysis now?' Marketing Theory 15(1): 38.

Colman, D. (2009) 'CConfessions of a Shopaholic': Buying that thing, right now', The New York Times. URL (consulted June 2018) https://www.nytimes.com/2009/02/13/arts/13ihtshop.1.20175678.html

Cornell, W.F. (1988) 'Life script theory: A critical review from a developmental perspective', Transactional Analysis Journal 18(4): 270-282.

Kinsella, S. (2009) Confessions of a Shopaholic (Vol. 1). Dell.

Kinsella, S. (2001) Shopaholic abroad. Random House.

Le Guernic, A. (2004) 'Fairy tales and psychological life plans', Transactional Analysis Journal 34(3): 216-222.

English, F. (1988) 'Whither scripts?’ Transactional Analysis Journal, 18(4): 294-303.

Erskine, R.G. and Zalcman, M.J. (1979) 'The racket system: A model for racket analysis', Transactional Analysis Bulletin 9(1): 51-59.

Falk, P. and Campbell, C. (1997) The shopping experience (Vol. 52). Sage. 
Fitchett, J. (2002) 'Marketing sadism: Super-Cannes and consumer culture', Marketing Theory 2(3): 309-322.

Fromm, E. (1976) To Have or to Be? London: Abacus.

Fromm, E. (1955) The Sane Society. New York: Rinehart \& Co.

Gabriel, Y. and Carr, A. (2002) 'Organizations, management and psychoanalysis: an overview', Journal of Managerial Psychology 17(5): 348-365.

Giesler, M. and Thompson, C.J. (2016) 'A Tutorial in Consumer Research: Process Theorization in Cultural Consumer Research', Journal of Consumer Research 43(4): 497 508.

Holmes, J. (2013) ‘A comparison of clinical psychoanalysis and research interviews', Human Relations 66(9): 1183-1199.

Illouz E (2007) Cold intimacies: The making of emotional capitalism. Polity: Cambridge. Inman, F. and Barr, C. (2017) 'Britain's debt timebomb: The UK's debt crisis - in figures', The Guardian. URL (consulted October 2017):

https://www.theguardian.com/business/2017/sep/18/uk-debt-crisis-credit-cards-car-loans

Jackson, T. (2009) 'Prosperity without growth? The transition to a sustainable economy', Sustainable Development Commission. URL (consulted May 2018) http://happymuseumproject.org/wpcontent/uploads/2013/02/Prosperity_without_growth_report.pdf

Karpman, S.B. (2011) 'Fairy tales and script drama analysis', Group Facilitation (11): 49.

Kearney, M. and Stevens, L. (2012) 'Compulsive buying: Literature review and suggestions for future research', The Marketing Review 12(3): 233-251.

Krantz, J. (1978) Scruples. Warner Books: London.

Kraepelin, E. and Diefendorf, A.R. (1915) Clinical psychiatry: a text-book for students and physicians. Macmillan. 
Marcuse, H. (1964) One-dimensional man: the ideology of advanced industrial society.

Croydon: Routledge \& Kegan Paul.

Marcuse, H. (1966) Eros and Civilization: Philosophical Inquiry Into Freud. Beacon Pr.

Martens, L. (2016) Gender and consumption: Domestic cultures and the commercialisation of everyday life. Routledge.

Mazzetti, M. (2010). Eric Berne and cultural script. Transactional Analysis Journal, 40(3-4): 187-195.

Mellor, K. and Schiff, E. (1975) 'Discounting’ Transactional Analysis Bulletin 5(3): 295-302.

Midgley, N. (2006) 'Psychoanalysis and qualitative psychology: Complementary or contradictory paradigms', Qualitative Research in Psychology 3(3): 213-232.

Mihailovic, K.P. and Mihailovic, D. (2004) 'The social matrix of globalization' Transactional Analysis Journal 34(4): 347-355.

Miles, C. (2015) 'Ericksonian therapy as a grounding for a theory of persuasive marketing dialogue', Marketing Theory 15(1): 95-111.

Miller, D. (2010) Stuff. Polity.

Miller, D. (2008) The comfort of things. Polity.

Miller, D. (1998) A theory of shopping. John Wiley \& Sons.

Miller, D. (1997) ‘Could Shopping every really matter?’ In: Falk, P. and Campbell, C. (eds.) The shopping experience (Vol. 52). Sage.

Molesworth, M., Grigore, G.F. and Jenkins, R. (2016) 'Games people play with brands: An application of Transactional Analysis to marketplace relationships', Marketing Theory 1470593117706530

Noriega, G. (2010) 'The transgenerational script of transactional analysis', Transactional Analysis Journal 40(3-4): 196-204.

Palahniuk, C. (2005). Fight Club: a novel. WW Norton \& Company. 
Patsiaouras, G., Fitchett, J. A. and Davies, A. (2016) 'Beyond the couch: Psychoanalytic consumer character readings into narcissism and denial', Marketing Theory 16(1): 57-73.

Patterson, A. and Brown, S. (2005) 'No tale, no sale: A novel approach to marketing communication', The Marketing Review 5(4): 315-328.

Quinn, J. (2017) 'Bank of England warns of 'pockets of risk' to growing £200bn consumer debt pile', The Telegraph. URL (consulted October 2017):

http://www.telegraph.co.uk/business/2017/09/25/bank-england-warns-pockets-riskgrowing-200bn-consumer-debt/

Radner, H. (2011). Neo-Feminist Cinema: Girly Films, Chick Flicks, and Consumer Culture. Routledge.

Scitovsky, T. (1976) The joyless economy: An inquiry into human satisfaction and consumer dissatisfaction.

Shankar, A., Whittaker, J. and Fitchett, J.A. (2006) 'Heaven Knows I'm Miserable Now', Marketing Theory 6(4): 485-505.

Solomon, M.R. (2014) Consumer behavior: Buying, having, and being. Upper Saddle River, Prentice Hall: NJ.

Steiner, C. (1974) Scripts people live: transactional analysis of life scripts. New York: Groove Press.

Stewart, I. and Joines, V. (2012) TA Today. A New Introduction to Transactional Analysis. Russell Press Ltd: Nottingham.

Svoboda, E. (2010) 'Field Guide to the Shopaholic', Psychology Today. URL (consulted October 2017): https://www.psychologytoday.com/articles/201009/field-guide-theshopaholic.

Tauber, E. M. (1972) 'Why do people shop?’ The Journal of Marketing October: 46-49.

Twitchell, J.B. (1999) 'Two cheers for materialism' The Wilson Quarterly 23(2): 16-26. 